\title{
Frontalis Muscle Flap Suspension Surgery for the Treatment of Blepharoptosis Based on the Anatomical Study of the Frontal Muscle Nerve in the Third of the Eyebrow
}

\author{
Cirugía de Suspensión del Colgajo Muscular Frontal en el Tratamiento de Blefaroptosis Basado en \\ el Estudio Anatómico del Nervio del Músculo Occipitofrontal en el Tercio de la Ceja
}

Lianbo Zhang"; Haiyan Qin*; Wanying Chen*; Zhuoxia Wu**; Zhi Li*; Jiao Kong"*; Feifei Chen*** Xingchao Jiang* Guang Zhang**

ZHANG, L.; QIN, H.; CHEN, W.; WU, Z.; LI, Z.; KONG, J.; CHEN, F.; JIANG, X. \& ZHANG, G. Frontal muscular flap suspension surgery for the treatment of blepharoptosis based on the anatomical study of the frontal muscle nerve in the third of the eyebrow. Int. J. Morphol., 34(1):197-204, 2016.

SUMMARY: The aim of this study was to investigate the course of the supraorbital nerve and temporal branch of the facial nerve, and to verify the clinical security of cutting the frontalis muscle flap to treat blepharoptosis in one-third of the eyebrow. Twenty cadavers were dissected. The relationship of the supraorbital nerve and the course of the frontotemporal branch of the facial nerve with the head and neck muscles was evaluated. Forty patients underwent clinical frontal muscular flap suspension surgery for the treatment of blepharoptosis. The postoperative curative and complication rates were determined. The courses of the supraorbital nerve and frontotemporal branch of the facial nerve were observed to determine a relatively safe area in one-third of the eyebrow. The average width of the zone was $25.0 \pm 3.5 \mathrm{~mm}$. In forty cases, satisfactory results were achieved in correcting blepharoptosis by cutting the frontal muscular flap in the middle of eyebrow within the wide range of $17 \pm 2.1 \mathrm{~mm}$. No secondary sensory and motor dysfunctions occurred. One-third of the eyebrow (eyebrow center, within $17 \pm 2.1$ $\mathrm{mm}$ ) was a relatively safe area and allowed for the prevention of damage to the temporal branch of the facial nerve inside the supraorbital nerve and supraorbital artery and the outer frontotemporal branch of the facial nerve.

KEY WORDS: Blepharoptosis; Frontalis muscle flap; Facial nerve; Anatomy.

\section{INTRODUCTION}

Blepharoptosis is a common eye abnormality, with an incidence rate of about $0.56 \%$, ranking second among congenital eye diseases (Lim et al., 2013). Its main manifestation is limited upper eyelid elevation and even occlusion amblyopia (El Essawy \& Elsada, 2013). According to statistics, the incidence rate of visual impairment in children younger than 4 y reached up to $78.2 \%$, and the impact of the appearance easily lead to disability (Stein $e t$ al., 2014; Zhong et al., 2014). For moderate to severe blepharoptosis, surgery is the only treatment, and the sooner the surgery, the lesser the impact on children, usually children older than 4 years can be treated with surgery (Allard \& Durairaj, 2010; Hou et al., 2013; Lee \& Ahn, 2014). Two main more-accepted treatments of blepharoptosis are currently available: one was to enhance the levator muscle strength by performing levator muscle shortening (Emsen, 2008) and the second was to perform surgery by enhancing frontalis muscle power via frontalis muscle suspension (Debski et al., 2012). However, the use of silk and other intermediaries is prone to infection or exclusion, or other complications. Therefore, blepharoptosis recurrence occurs and reoperation is usually required (Hayashi et al., 2013). The direct use of the frontalis muscle flap may prevent the above-mentioned problems, and the frontalis muscle flap had an independent vascular supply and innervation, which has become the preferred method of clinical treatment of blepharoptosis (Medel et al., 2014). To achieve better surgical results and prevent complications caused by an unclear anatomy, we studied frontalis muscle nerves dominated by blood vessels in order to provide an anatomical basis for the clinical use of the frontalis muscle flap in the correction of blepharoptosis.

\section{MATERIAL AND METHOD}

Twenty adult cadavers fixed in $10 \%$ formalin solution, including 10 males and 10 females, for a total of 40 sides, were included. Cadavers with frontal lesions and unknown age were excluded.

\footnotetext{
* Department of Plastic Surgery, China-Japan Union Hospital of Jilin University, Changchun 130033, China.

** Department of Thyroid Surgery, China-Japan Union Hospital of Jilin University, Changchun 130033, China.
} 
ZHANG, L.; QIN, H.; CHEN, W.; WU, Z.; LI, Z.; KONG, J.; CHEN, F.; JIANG, X. \& ZHANG, G. Frontal muscular flap suspension surgery for the treatment of blepharoptosis based on the anatomical study of the frontal muscle nerve in the third of the eyebrow. Int. J. Morphol., 34(1):197-204, 2016.

Exposing anatomical regions. The incision line was designed with a longitudinal vertical dash according to the designated points $\mathrm{A}, \mathrm{B}, \mathrm{C}$, and $\mathrm{D}$ in three equal parts of the eyebrows. The skin was cut on the surface and subcutaneous tissues at the eyebrow until the incision reached the lower orbicularis muscles. The skin was peeled by using a peeler. Points A, B, C, and D located on vertical lines were set in the muscle layer with methylene blue. The supraorbital neurovascular bundle and temporal branch of the facial nerve were identified, and their courses were observed.

Measurements of the experimental data. The following indicators were measured: the length of the eyebrows were strictly divided into three equal portions as follows: the starting point near the midline was point $\mathrm{A}$, the two divisions were points $\mathrm{B}$ and $\mathrm{C}$, and the end was point $\mathrm{D}$, apart from the midline, supraorbital neurovascular bundles and the outer diameter of the temporal branch of the facial nerve, the intersection of supraorbital nerve and facial nerve temporal branch, and the incision distance from the midline and supraorbital neurovascular bundle course, respectively. The average of three measurements were recorded, and the results were expressed as Mean \pm SD.

Clinical data. From April 2008 to April 2014, 28 male and 12 female patients were selected, including 31 patients with blepharoptosis and 9 with unilateral blepharoptosis. Of the cases, 37 were congenital and 3 were traumatic. The patients' ages ranged from 3 to $45 \mathrm{y}$. In the measurement with eyes straight ahead, the upper eyelid covered $6-8 \mathrm{~mm}$ of the cornea (average, $7.2 \mathrm{~mm}$ ), the levator muscle strength was $0-3 \mathrm{~mm}$, and the rectus functions were good. Four patients had mild amblyopia, and one had mild strabismus. This study was conducted in accordance with the Declaration of Helsinki. This study was conducted with approval by the ethics committee of Jilin University. Written informed consent was obtained from all of the participants.

Surgery. In combination with the above-mentioned anatomical methods, the following are needed: First is adjustment of the position. The patients were asked to look straight ahead for measurement of the length of the upper edge for eyelid distance from the cornea. Generally, it should be located $1 \mathrm{~mm}$ above the upper edge of the cornea when the eyes are opened. The upper eyelid would cover $1 \mathrm{~mm}$ over the lower edge of the cornea when the eyes are closed. After adjusting the position of the patients, the frontal muscular and pretarsal fascia were sutured (Goldberg \& Lew, 2011; Bagheri et al., 2012). Second is the formation of the double eyelid. The incision was sutured by using $8-0$ sutures. No damaged line due to the double eyelid surgery was observed, and then the eyebrow incision was sutured by using 7-0 sutures. No damaged suture line was observed. An elastic bandage was used to wrap the forehead for $24 \mathrm{~h}$. The stitches were removed about $5 \mathrm{~d}$ after the operation.

Determine the efficacy. Efficacy was judged comprehensively based on the objective indicators after surgery such as morphology and eye function, as well as whether complications occurred. In terms of satisfaction, the appearance was ideal. The activity range of the upper eyelid was $\geq 8 \mathrm{~mm}$, the blepharophimosis height was about $8-10$ $\mathrm{mm}$, the outcome was symmetrical, and the long-term effect was improved. Compared with that before surgery, the appearance improved significantly, but the blepharophimosis height was between 5 and $8 \mathrm{~mm}$. The appearance looked a quite stiff. The long-term effect was generally acceptable. The blepharoptosis did not significantly improve compared with that before surgery.

Statistical analysis. Analysis of variance was used for statistical analysis.

\section{RESULTS}

Length of the eyebrows. In the eyebrow area, eyebrow frown muscles were observed on the deep surface of the eyebrows, starting from the superior orbital rim. The supraorbital neurovascular bundle and trochlear nerve course was visible on the deep surface. Therefore, the location of the eyebrow had a certain guide role for identifying deep surface structures. Based on the length of the eyebrows, the eyebrow was strictly trisected. The point closer to the midline was the starting point, the two divisions were points B and $\mathrm{C}$, and the end point was $\mathrm{D}$. The distance from the midline for the men and women were respectively $10.06 \pm 2.08 \mathrm{~mm}$ and $9.58 \pm 2.16 \mathrm{~mm}$ for $\mathrm{A}, 32.36 \pm 5.88 \mathrm{~mm}$ and $30.42 \pm 6.24$ $\mathrm{mm}$ for $\mathrm{B}, 57.28 \pm 8.50 \mathrm{~mm}$ and $55.76 \pm 8.64 \mathrm{~mm}$ for $\mathrm{C}$, and $80.22 \pm 12.72 \mathrm{~mm}$ and $76.46 \pm 11.36 \mathrm{~mm}$ for $\mathrm{D}$. The total lengths of the eyebrows for the men and women were $68.26 \pm 10.52 \mathrm{~mm}$ and $60.84 \pm 11.66 \mathrm{~mm}$, respectively. The specific anatomical location is shown in Table I and Figure 1.

Frontal muscle-related data. The frontal muscle was the forehead abdomen of the occipitofrontalis muscle in the shape of a square, located in the deep surface of the skin and superficial fascia of the forehead. The back end continued to the subgaleal fascia. The front was sectioned to be two shallow and deep parts in the slightly upper part of the eyebrow. Among them, the muscle fibers of the shallow part were attached to the skin above the eyebrow, which was the measured part, and a notable difference was observed between the men and the women (Djordjevic et al., 2013). The average lengths of the inner frontal muscle edge were 
ZHANG, L.; QIN, H.; CHEN, W.; WU, Z.; LI, Z.; KONG, J.; CHEN, F.; JIANG, X. \& ZHANG, G. Frontal muscular flap suspension surgery for the treatment of blepharoptosis based on the anatomical study of the frontal muscle nerve in the third of the eyebrow. Int. J. Morphol., 34(1):197-204, 2016.

Table I. The ABCD points after three equal divisions of the eyebrow distance from the midline (mm).

\begin{tabular}{lccccc}
\hline Sex & Length of eyebrow & A & B & C & D \\
\hline Male & $68.26 \pm 10.52$ & $10.06 \pm 2.08$ & $32.36 \pm 5.88$ & $57.28 \pm 8.50$ & $80.22 \pm 12.72$ \\
Female & $60.84 \pm 11.66$ & $9.58 \pm 2.16$ & $30.42 \pm 6.24$ & $55.76 \pm 8.64$ & $76.46 \pm 11.36$ \\
\hline
\end{tabular}

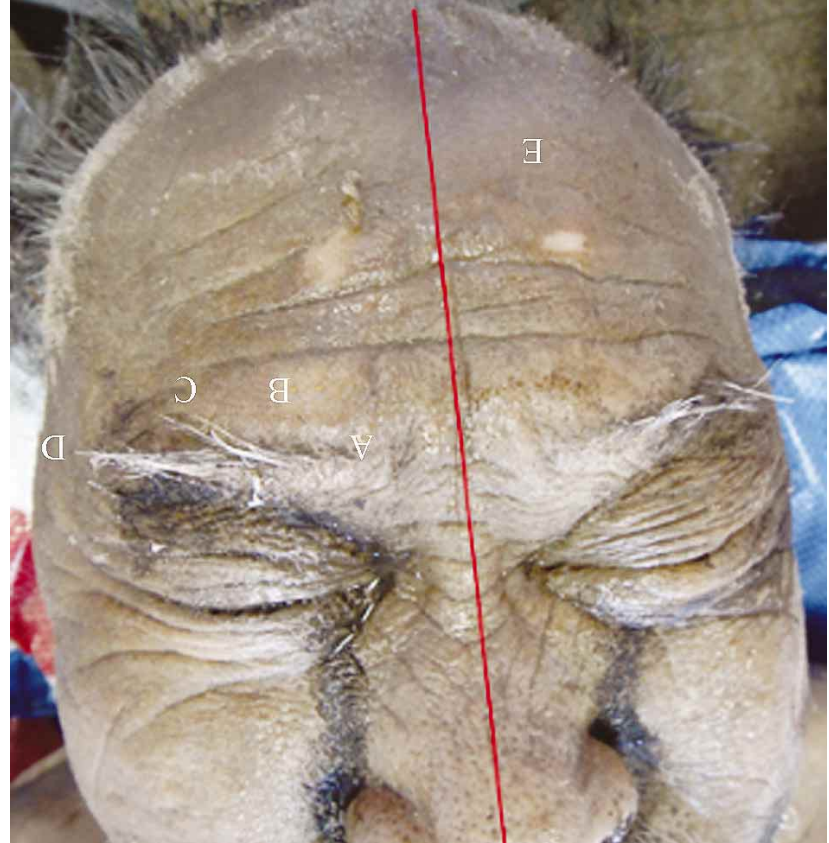

Fig. 1. Eyebrow length. A, B, C, D: four points trisected the eyebrow. E: frontal midline.

$65.78 \pm 0.85 \mathrm{~mm}$ for the left side and $65.49 \pm 0.88 \mathrm{~mm}$ for the right side. The average lengths of the outer frontal muscle edge were $70.48 \pm 0.95 \mathrm{~mm}$ and $70.55 \pm 0.94 \mathrm{~mm}$, respectively. The average lengths of the front width were $56.14 \pm 0.75 \mathrm{~mm}$ and $55.93 \pm 0.74 \mathrm{~mm}$, respectively. The average lengths of the rear width were $61.09 \pm 0.82 \mathrm{~mm}$ and $60.40 \pm 0.83 \mathrm{~mm}$, respectively. The average lengths of the middle thickness were $1.43 \pm 0.06 \mathrm{~mm}$ and $1.46 \pm 0.06 \mathrm{~mm}$, respectively. The specific anatomic data are shown in Table II and Figure 2.

Supraorbital nerve anatomy. The supraorbital nerve was not completely straight after walking of the supraorbital foramen, but directed from the inner low to the outer upper directions at a certain angle. The trunk course was the frontal muscle fascia and subgaleal gapline. The vertical course was its inside branch, while the outside branches tended to be directed outside (Konofaos et al., 2013; Christensen et

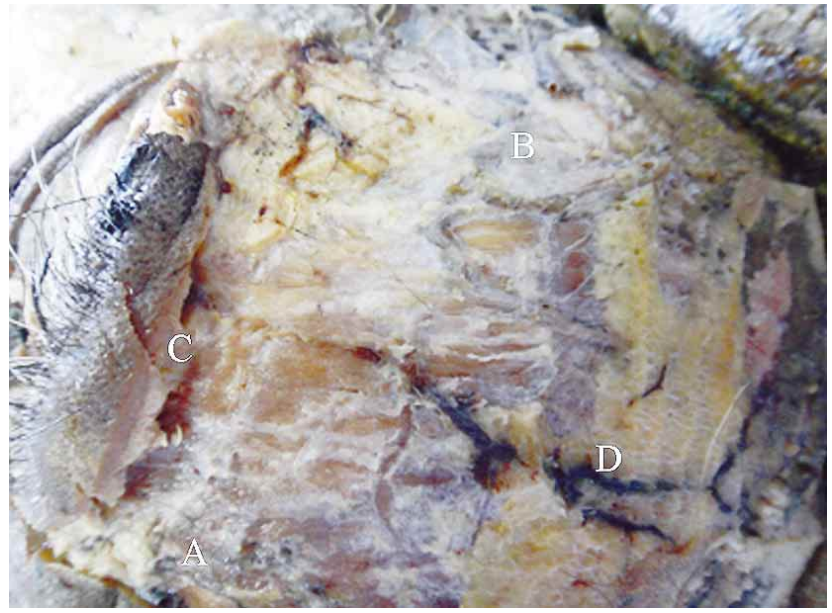

Fig. 2. Frontal muscle anatomy. A, inside edge of frontal edge. B, outside edge of frontal edge. C, front edge of frontal edge. D, rear edge of frontal edge.

al., 2014). The supraorbital nerve entering the point position, the trunk diameter, and the angle between the tangent of the supraorbital foramen were our measured parts. The diameter of the supraorbital nerve trunk out of the supraorbital foramen was $1.44 \pm 0.3 \mathrm{~mm}$. The straight distance of the muscle points to the supraorbital foramen was $40.3 \pm 9.0 \mathrm{~mm}$. The vertical distance was $33.7 \pm 8.5 \mathrm{~mm}$, the horizontal distance was $30.5 \pm 8.6 \mathrm{~mm}$, the angle of the trunk and the tangent supraorbital foramen was $52.7 \pm 7.4^{\circ}$; the trunk of the supraorbital artery accompanied the supraorbital nerve from the supraorbital foramen (Tables III and IV; Fig. 3).

Supraorbital artery dissection. The supraorbital artery was the branch of the ophthalmic artery, passing through the supraorbital foramen with the supraorbital nerve. Its trunk passed through the outer upper direction at an angle, horizontally through the frontal muscle and posterior sheath of subgaleal at about the midpoint of the forehead. The supraorbital artery was located at the horizontal lines of the supraorbital margin and the frontal midline midpoint, at a distance of $22.5 \pm 4.1 \mathrm{~mm}$ and $33.3 \pm 5.9 \mathrm{~mm}$ from the midline, respectively. The distances from the supraorbital artery from the midline are shown in Table V and Figure 4.

Table II. Measurement of frontal muscle (mm).

\begin{tabular}{llccccc}
\hline Sex & & Inner edge length & Outer edge length & Frontal width & Rear width & Middle thickness \\
\hline Male & Left & $66.19 \pm 0.88$ & $71.02 \pm 1.06$ & $56.43 \pm 0.85$ & $61.40 \pm 0.88$ & $1.46 \pm 0.04$ \\
& Right & $65.86 \pm 0.87$ & $70.94 \pm 1.17$ & $56.02 \pm 0.81$ & $60.48 \pm 0.92$ & $1.48 \pm 0.05$ \\
Female & Left & $63.76 \pm 1.29$ & $68.08 \pm 1.38$ & $54.75 \pm 1.60$ & $59.56 \pm 2.10$ & $1.37 \pm 0.06$ \\
& Right & $63.84 \pm 1.22$ & $68.60 \pm 1.28$ & $55.49 \pm 1.46$ & $60.16 \pm 1.71$ & $1.37 \pm 0.07$
\end{tabular}


Table III. Muscle entering points of supraorbital nerve (mm).

\begin{tabular}{lccc}
\hline & $\begin{array}{c}\text { Straight distance of muscle } \\
\text { entering points from the } \\
\text { supraorbital for amen }\end{array}$ & $\begin{array}{c}\text { Vertical distance of muscle } \\
\text { entering points from the } \\
\text { supraorbital foramen }\end{array}$ & $\begin{array}{c}\text { Horizontal distance of muscle } \\
\text { entering points from the } \\
\text { supraorbital foramen }\end{array}$ \\
\cline { 2 - 4 } Mean \pm SD & $40.32 \pm 6.01$ & $33.71 \pm 5.55$ & $30.55 \pm 5.63$ \\
Max & 47.32 & 40.04 & 36.18 \\
Min & 35.28 & 29.38 & 26.24 \\
\hline
\end{tabular}

Table IV. The diameter of trunk out of supraorbital foramen and the angle of tangent of supraorbital foramen $\left(^{\circ}\right)$.

\begin{tabular}{lcc}
\hline & $\begin{array}{c}\text { Diameter of trunk out of } \\
\text { supra orbital foramen }\end{array}$ & $\begin{array}{c}\text { Angle of tangent of } \\
\text { supraorbital foramen }\end{array}$ \\
\cline { 2 - 3 } Mean \pm SD & $1.44 \pm 0.32$ & $52.73 \pm 6.41$ \\
Max & 1.78 & 60.16 \\
Min & 1.02 & 47.24 \\
\hline
\end{tabular}

Anatomy of the temporal branch of the facial nerve. Most of the temporal branch of the facial nerve went to the lower front of the superficial temporal artery frontal branch, entered into the deep surface of frontal muscle through the upper part of orbicularis muscle, and the outer edge of the frontal muscle. A small part went through the surface of the frontal branch and had traffic branches to support each other. The distances of the lowest and highest points of the temporal branch of the facial nerve entering the frontal muscle from the supraorbital margin were $7.6 \pm 1.5 \mathrm{~mm}$ and $26.4 \pm 3.0 \mathrm{~mm}$, and their distance from the midline were $50.0 \pm 1.9 \mathrm{~mm}$ and $51.3 \pm 2.1 \mathrm{~mm}$, respectively. The specific anatomic data are shown in Table VI and Figure 5.

Clinical effect. In this study, 40 patients were selected. The minimum follow-up time was 1 month, and the maximum was 18 months, with an average of 6 months. In the 1-week follow-up, no significant asymmetry was found in the eyes, but with different degrees of obstacles during eye closure. Topical ointment was needed to protect the eye at night. In the 3-month follow-up, the eye closure disorders largely disappeared, double eyelid radians were relatively smooth, the appearance was natural and symmetrical, no complications such as inverted upper eyelid were observed, no hair removal phenomenon in the eyebrow incision was observed, and the scar was gradually inconspicuous. The outcome in one eye for 30 cases and two eyes for

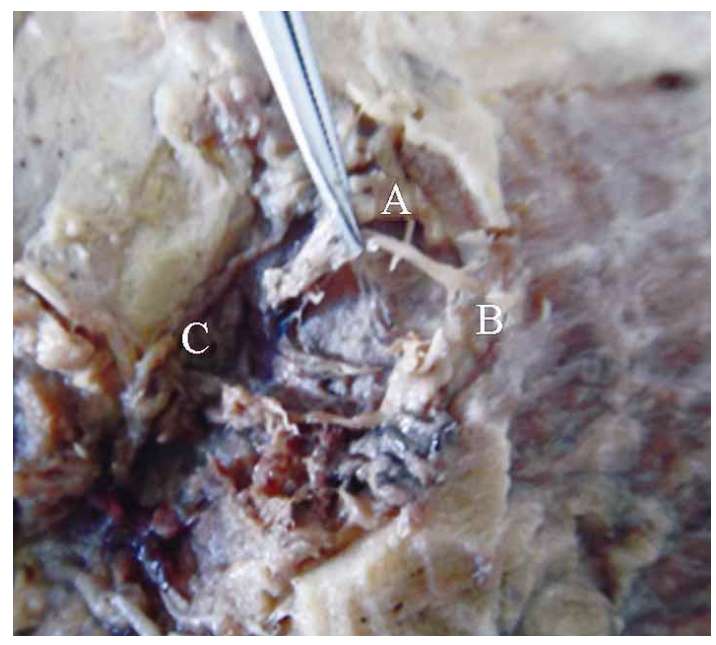

Fig. 3. Supraorbital nerve anatomy. A, supraorbital nerve. $\mathrm{B}$, supraorbital nerve entering point. $\mathrm{C}$, supraorbital hole.

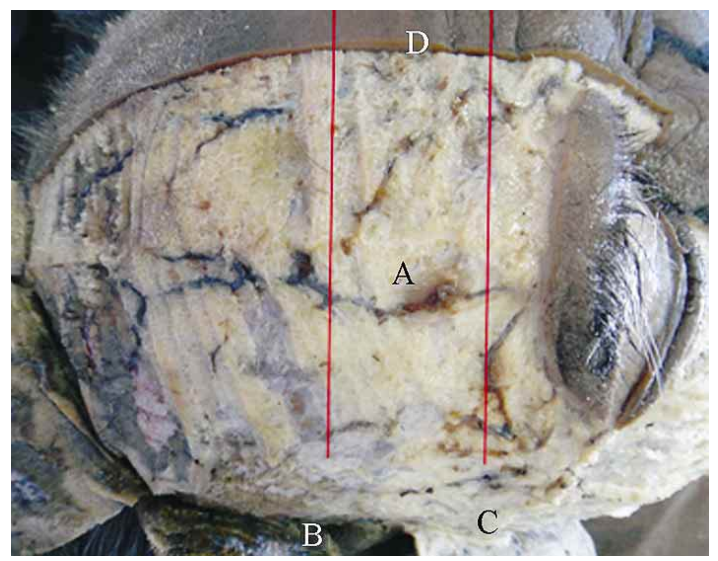

Fig. 4. Supraorbital artery dissection. A, supraorbital artery. B, horizontal level of frontal midpoint. C, supraorbital margin level. D, midline.

Table V. Supraorbital artery distance from the midline $(\mathrm{mm})$.

\begin{tabular}{lcc}
\hline & $\begin{array}{c}\text { Supraorbital artery distance from } \\
\text { the midline in supraorbital line }\end{array}$ & $\begin{array}{c}\text { Supraorbital artery distance from the } \\
\text { midline in the midpoint line of forehead }\end{array}$ \\
\cline { 2 - 3 } Mean \pm SD & $22.55 \pm 4.12$ & $33.33 \pm 5.91$ \\
Max & 28.16 & 38.82 \\
Min & 19.22 & 27.14 \\
\hline
\end{tabular}

Table VI. The lowest and the highest points of temporal branch of the facial nerve entering the frontal muscle $(\mathrm{mm})$.

\begin{tabular}{lcc}
\hline & The lowest point & The highest point \\
\hline Distance from the supraorbital edge & $7.62 \pm 1.54$ & $26.44 \pm 3.02$ \\
Distance from the midline & $50.05 \pm 1.93$ & $51.36 \pm 2.11$ \\
\hline
\end{tabular}




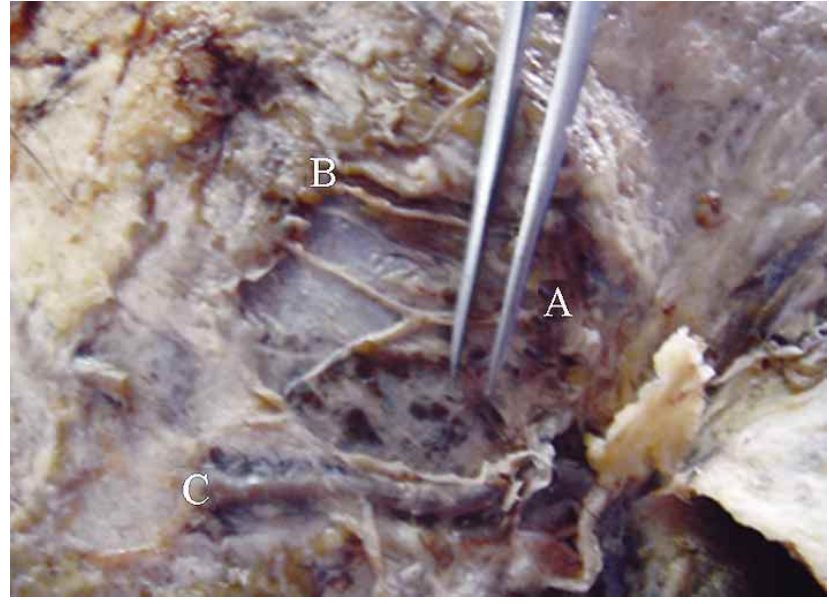

Fig. 5. Temporal branch of the facial nerve. A, temporal branch of the facial nerve. B, the lowest point. $\mathrm{C}$, the highest point.

eight cases were quite satisfactory. When the eyes looked straight ahead, $95 \%$ of the upper eyelid was located $1-2$ $\mathrm{mm}$ on the edge of the cornea. The outcome of one eye for one case had good results, accounting for $2.5 \%$. Only one side in one patient with blepharoptosis showed poor sagging and relapse after 2 months. It was better than that before surgery. Frontal muscle flap suspension surgery was repeated. The outcome at 3 months was observed to be quite satisfactory, accounting for $2.5 \%$ (Fig. 6).

\section{DISCUSSION}

First, this study measured the length and distance between the point and the midline of the flags eyebrows, which can be used as incision site in clinical practice and should be paid attention. In the measurement, the length of the eyebrows was found to have individual differences, which do not exactly coincide with the superciliary arch, strictly trisected according to the length of the eyebrow was not entirely applicable to the superciliary arch. This reminds us that in clinical practice, the incision should be offset slightly inward for patients with longer eyebrows.

The supraorbital supraorbital nerve was not completely straight up after passing through the supraorbital foramen, but from the inner lower to the outer upper direction at a certain angle. The trunk course was the frontal muscle fascia and subgaleal gapline. The vertical course was its inside branch, jointly distributed between the skin of the forehead. The author obtained the diameter of the supraorbital nerve trunk out of the supraorbital foramen, which was $1.44 \pm 0.3 \mathrm{~mm}$. The straight distance of the muscle points to the supraorbital foramen was $40.3 \pm 9.0 \mathrm{~mm}$. The vertical distance was $33.7 \pm 8.5 \mathrm{~mm}$. The horizontal distance was $30.5 \pm 8.6 \mathrm{~mm}$. The angle of the trunk and the tangent supraorbital foramen was $52.7 \pm 7.4^{\circ}$. Huang et al. (2012) also reported that the diameter of the supraorbital nerve trunk out of the supraorbital foramen was $1.43 \pm 0.3 \mathrm{~mm}$. The straight distance of the muscle points to the supraorbital foramen was $40.2 \pm 9.1 \mathrm{~mm}$. The vertical distance was $33.8 \pm 8.4$ $\mathrm{mm}$. The horizontal distance was $30.5 \pm 8.7 \mathrm{~mm}$. The angle of the trunk and the tangent supraorbital foramen was $52.8 \pm 7.4^{\circ}$.

The author believed that in the separation and cutting of the frontal muscle flap, the supraorbital nerve must have courses in the deep surface within the separate area.

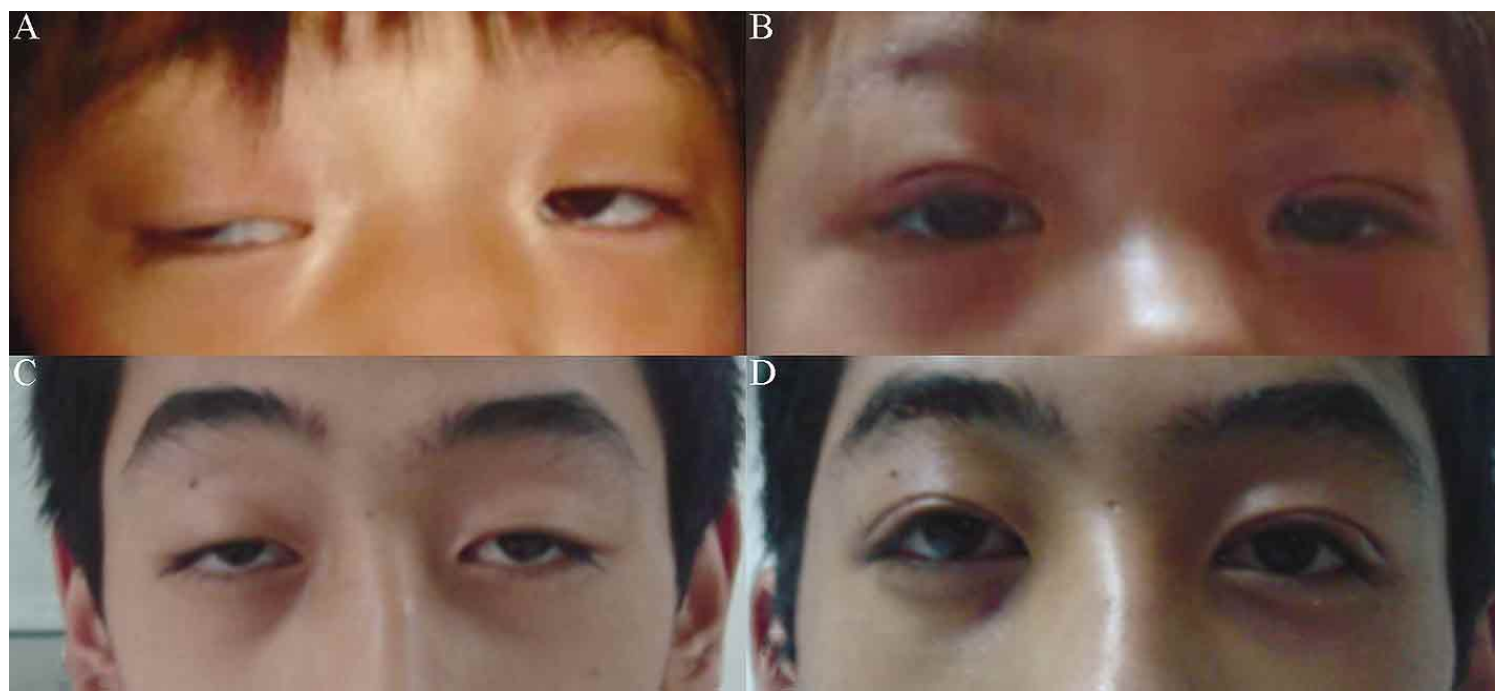

Fig. 6. Effect of ptosis surgery. Up: A 3-year-old girl with severe congenital ptosis. A, before ptosissurgery. B, One month after ptosis surgery. Down: A 17-year-old boy with severe congenital ptosis. C, before ptosis surgery. D, one week after ptosis surgery. 
Therefore, during the operation, when the frontal fascia needs to be cut, it should be separated up on the deep face of the frontal muscle and brought up the frontal muscle to avoid injury to the deep surface of the supraorbital nerve. In the operation of longitudinal cutting from the frontal muscle flap to the free muscle flap over the supraorbital holes, the supraorbital nerve obliquely should be shifted on the deep surface of the frontal muscle and carefully freed the connective tissue around the nerve (Kemp et al., 2011).

The temporal branch of the facial nerve is one of the five branches of the facial nerves, which pierces the upper edge of the parotid gland, crosses the zygomatic arch to reach the temporal region, and dominates the frontal belly of the occipitofrontalis muscle, orbicularis muscle, and others (Davies et al., 2012). The distances of the lowest and highest points of the temporal branch of the facial nerve above, entering the frontal muscle from the supraorbital margin, were $7.6 \pm 1.5 \mathrm{~mm}$ and $26.4 \pm 3.0 \mathrm{~mm}$, respectively. Their distances from the midline were $50.0 \pm 1.9 \mathrm{~mm}$ and $51.3 \pm 2.1 \mathrm{~mm}$, respectively. Zhao et al. (2011) also measured that the distances of the lowest and highest points of the temporal branch of the facial nerve above, entering the frontal muscle from the supraorbital margin and obtained $7.5 \pm 1.6 \mathrm{~mm}$ and $26.5 \pm 2.9 \mathrm{~mm}$, respectively. Their distances from the midline were $50.1 \pm 1.8 \mathrm{~mm}$ and $51.2 \pm 2.1$ $\mathrm{mm}$, respectively. Our measurement results were similar to those in their report, but the measured angle of the supraorbital nerve trunk and the tangent of the supraorbital hole was slightly larger than the results measured by Yang et al. (2013), which may be related with the degree of the fixed cadavers.

The temporal branch of the facial nerve penetrated deep to the outside of the frontal muscle at the outer edge of the frontal muscle. Its main role was to support the frontal and orbicularis muscles, while the temporal branch of the facial nerve mainly distributed on the outside of the frontal muscle. Thus, in the process of transverse or longitudinal incision to take the frontal muscle flap, the outside incision of the frontal muscle should be avoided in order to prevent the loss of the temporal branch of the facial nerve (de Bonnecaze et al., 2015).

The study also measured the distance of the horizontal line of the supraorbital margin supraorbital artery, horizontal line of the frontal midpoint from the midline. The supraorbital artery passed through the supraorbital foramen, accompanied with the supraorbital nerve. Thus, the distance was considered to be the supraorbital nerve distance, which may be better for positioning the supraorbital nerve course to prevent to damage the supraorbital neurovascular bundle.
The results of this study showed that the third of the eyebrow was a relatively safe area if the incision was designed to be made at the lower edge of one-third of the eyebrow. Possible damage to the supraorbital nerve and supraorbital artery located inside in a large degree could be prevented, as well as damage to the outside temporal branch of the facial nerve.

In addition, in the process of cutting and separating the rectangular flap, surgeons should pay attention not only to the cutting position but also to the incision depth, which is due to the supraorbital neurovascular bundle course in the deep surface of the frontal muscle. Thus, in making a rectangular incision, it was preferable to lift the frontal muscle to cut the frontal muscle and periosteum gap. If the incision was too deep, it may damage the supraorbital neurovascular bundle of the trunk or branches.

In the process of collecting clinical cases, this study also refined some case-related surgery operations and key points, and precautions after surgery, and in contrast with the basic anatomy research data to obtain precautionary measures.

Double eyelid line should not be distanced from the eyelid edge by more than $7 \mathrm{~mm}$ in order to prevent an unnatural, exaggerated appearance. For aged patients, part of the skin on the upper eyelid can be removed depending on the circumstances of their own loose skin (Maegawa et al., 2012). The incision in the eyebrow should be located outside of three equal portions. The incision is best located along the growth direction of the eyebrows, taking care that the hair follicle is not damaged. Blunt dissection should be used to separate the frontal muscle in order to avoid damage to the outside temporal branch of the facial nerve and the inside supraorbital nerve. The forehead had rich blood supply, which was prone to bleeding in blunt dissection. Hence, oppression needs to be performed separately in order to reduce bleeding. A too narrow subcutaneous tunnel will affect the blood supply to the frontal muscle flap. In the suture of the frontal muscle and tarsus front fascia, a few more sutures should be performed in order to reduce the risk of postoperative recurrence (Skaat et al., 2013; SooHoo et al., 2014).

During surgery, the stripping range was relatively large in interception of the frontal muscle flaps, making it prone to local hematoma. Therefore, an elastic bandage was necessary to wrap the forehead within $24 \mathrm{~h}$ after surgery. However, attention should be paid to avoid eye oppression or conjunctival edema, which slows down patients' recovery. After surgery, except during sleep, the head should be kept at a high level in order to promote local edema absorption. The short-term incomplete closure of the upper eyelid caused by appropriate correction exposed the cornea to air. In order to avoid keratoconjunctivitis infection due to exposure, eye drops were 
needed during the day and erythromycin ointment was applied at night (Pacella \& Codner, 2010). After stitch removal, patients should regularly practice opening and closing their eyes in order to accelerate recovery. Thus, although frontal muscle suspension surgery is more complicated, surgeons should pay attention to intraoperative and postoperative precautions. Performing the procedure in relatively safe areas may be the best way to treat severe blepharoptosis (Stiglmayer et al., 2004; Gundeslioglu et al., 2013).

\section{CONCLUSION}

One-third of the eyebrow was a relatively safe area, with an average zone width of $25.0 \pm 3.5 \mathrm{~mm}$. A more-preci- se incision of the inner edge of the frontal muscle located in the middle of the forehead, $3.0 \pm 0.6 \mathrm{~mm}$ outside the division $B$ point. Meanwhile, the supraorbital margin was at onethird of the eyebrow. The outer edge was $5.0 \pm 0.8 \mathrm{~mm}$ inside point $C$. This means that the wide range of $25-3-5=17 \pm 2.1$ $\mathrm{mm}$ prevented damage to the inside supraorbital nerve, supraorbital artery, and the outside temporal branch of the facial nerve as much as possible.

\section{ACKNOWLEDGEMENTS}

This work was funded by National Natural Science Foundation of China ( $\left.\mathrm{N}^{\mathrm{o}} 81372068\right)$.

ZHANG, L.; QIN, H.; CHEN, W.; WU, Z.; LI, Z.; KONG, J.; CHEN, F.; JIANG, X. \& ZHANG, G. Cirugía de suspensión del colgajo muscular frontal en el tratamiento de blefaroptosis basado en el estudio anatómico del nervio del músculo occipitofrontal en el tercio de la ceja. Int. J. Morphol., 34(1):197-204, 2016.

RESUMEN: El objetivo de este estudio fue investigar el curso del nervio supraorbital y la rama temporal del nervio facial, para verificar la seguridad clínica de cortar el vientre frontal del músculo occipitofrontal (colgajo de músculo frontal) para tratar la blefaroptosis en un tercio de la ceja. Veinte cadáveres fueron disecados. Se evaluó la relación del nervio supraorbital y el curso de la rama temporal del nervio facial con los músculos de la cabeza y cuello. Cuarenta pacientes fueron sometidos a la cirugía de confección del colgajo del músculo frontal para el tratamiento de la ptosis palpebral. Se determinaron las tasas de curación y de complicaciones postoperatorias. Se observaron los cursos del nervio supraorbital y la rama temporal del nervio facial para determinar un área relativamente segura en un tercio de la ceja. El ancho medio de la zona fue 25,0 $\pm 3,5 \mathrm{~mm}$. En cuarenta casos, se lograron resultados satisfactorios en la corrección de la blefaroptosis con el colgajo del músculo frontal en la mitad de la ceja en un rango de $17 \pm 2,1 \mathrm{~mm}$. No se produjeron disfunciones sensoriales o motoras secundarias. El tercio de la ceja (centro del entrecejo, dentro de $17 \pm 2,1 \mathrm{~mm}$ ) es una zona relativamente segura y permite la prevención de daños al ramo temporal del nervio facial ubicada medial al nervio supraorbitario y a la arteria supraorbitaria, además del ramo temporal lateral del nervio facial.

PALABRAS CLAVE: Blefaroptosis; Colgajo de músculo frontal; Músculo occipitofrontal; Nervio facial; Anatomía.

\section{REFERENCES}

Allard, F. D. \& Durairaj, V. D. Current techniques in surgical correction of congenital ptosis. Middle East Afr. J. Ophthalmol., 17(2):129-33, 2010.

Bagheri, A.; Ahadi, H.; Babsharif, B.; Salour, H. \& Yazdani, S. Direct tarsus to frontalis muscle sling without flap creation for correction of blepharoptosis with poor levator function. Orbit, 31(1):48-52, 2012.

Christensen, K. N.; Lachman, N.; Pawlina, W. \& Baum, C. L. Cutaneous depth of the supraorbital nerve: a cadaveric anatomic study with clinical applications to dermatology. Dermatol. Surg., 40(12):1342-8, 2014.

Davies, J. C.; Fattah, A.; Ravichandiran, M. \& Agur, A. M. Clinically relevant landmarks of the frontotemporal branch of the facial nerve: a three-dimensional study. Clin. Anat., 25(7):858-65, 2012. de Bonnecaze, G.; Chaput, B.; Filleron, T.; Al Hawat, A.; Vergez, S. $\&$ Chaynes, P. The frontal branch of the facial nerve: can we define a safety zone? Surg. Radiol. Anat., 37(5):499-506, 2015.

Debski, T.; Jethon, J.; Pietruski, P. \& Radzikowska, E. Frontalis suspension using autogenous fascia lata--evaluation of longterm outcome. Klin. Oczna, 114(3):198-203, 2012.

Djordjevic, B.; Novakovic, M.; Milisavljevic, M.; Milicevic, S. \& Malikovic, A. Surgical anatomy and histology of the levator palpebrae superioris muscle for blepharoptosis correction. Vojnosanit. Pregl., 70(12):1124-31, 2013.

El Essawy, R. \& Elsada, M. A. Clinical and demographic characteristics of ptosis in children: a national tertiary hospital study. Eur. J. Ophthalmol., 23(3):356-60, 2013.

Emsen, I. M. A new ptosis correction technique: a modification 
ZHANG, L.; QIN, H.; CHEN, W.; WU, Z.; LI, Z.; KONG, J.; CHEN, F.; JIANG, X. \& ZHANG, G. Frontal muscular flap suspension surgery for the treatment of blepharoptosis based on the anatomical study of the frontal muscle nerve in the third of the eyebrow. Int. J. Morphol., 34(1):197-204, 2016.

of levator aponeurosis advancement. J. Craniofac. Surg., 19(3):669-74, 2008.

Goldberg, R. A. \& Lew, H. Cosmetic outcome of posterior approach ptosis surgery (an American Ophthalmological Society thesis). Trans. Am. Ophthalmol. Soc., 109:157-67, 2011.

Gundeslioglu, A. O.; Selimoglu, M. N. \& Bekerecioglu, M. An frontalis sling operation using an autogenous en-bloc, fanshaped tensor fascia lata graft for blepharoptosis. J. Plast. Reconstr. Aesthet. Surg., 66(2):224-30, 2013.

Hayashi, K.; Katori, N.; Kasai, K.; Kamisasanuki, T.; Kokubo, K. \& Ohno-Matsui, K. Comparison of nylon monofilament suture and polytetrafluoroethylene sheet for frontalis suspension surgery in eyes with congenital ptosis. Am. J. Ophthalmol., 155(4):654-663.e1, 2013.

Hou, D.; Li, G.; Fang, L. \& Li, B. Frontalis muscle flap suspension for the correction of congenital blepharoptosis in early age children. PLoS One, 8(1):e53185, 2013.

Huang, A. T.; Tarasidis, G.; Yelverton, J. C. \& Burke, A. A novel advancement flap for reconstruction of massive forehead and temple soft-tissue defects. Laryngoscope, 122(8):1679-84, 2012.

Kemp, W. J. $3^{\text {rd }}$; Tubbs, R. S. \& Cohen-Gadol, A. A. The innervation of the scalp: A comprehensive review including anatomy, pathology, and neurosurgical correlates. Surg. Neurol. Int., 2:178, 2011.

Konofaos, P.; Soto-Miranda, M. A.; Ver Halen, J. \& Fleming, J. C. Supratrochlear and supraorbital nerves: an anatomical study and applications in the head and neck area. Ophthal. Plast. Reconstr. Surg., 29(5):403-8, 2013.

Lee, E. I. \& Ahn, T. J. Mild ptosis correction with the stitch method during incisional double fold formation. Arch. Plast. Surg., 41(1):71-6, 2014

Lim, J. M.; Hou, J. H.; Singa, R. M.; Aakalu, V. K. \& Setabutr, P. Relative incidence of blepharoptosis subtypes in an oculoplastics practice at a tertiary care center. Orbit, 32(4):2314, 2013.

Maegawa, J.; Kobayashi, S.; Yabuki, Y.; Hirotomi, K.; Yasumura, K. \& Iwai, T. Blepharoplasty in senile blepharoptosis: preoperative measurements and design for skin excision. Aesthet. Surg. J., 32(4):441-6, 2012.

Medel, R.; Vasquez, L. \& Wolley Dod, C. Early frontalis flap surgery as first option to correct congenital ptosis with poor levator function. Orbit, 33(3):164-8, 2014.

Pacella, S. J. \& Codner, M. A. Minor complications after blepharoplasty: dry eyes, chemosis, granulomas, ptosis, and scleral show. Plast. Reconstr. Surg., 125(2):709-18, 2010.
Skaat, A.; Fabian, D.; Spierer, A.; Rosen, N.; Rosner, M. \& Ben Simon, G. J. Congenital ptosis repair-surgical, cosmetic, and functional outcome: a report of 162 cases. Can. J. Ophthalmol., 48(2):93-8, 2013.

SooHoo, J. R.; Davies, B. W.; Allard, F. D. \& Durairaj, V. D. Congenital ptosis. Surv. Ophthalmol., 59(5):483-92, 2014.

Stein, A.; Kelly, J. P. \& Weiss, A. H. Congenital eyelid ptosis: onset and prevalence of amblyopia, associations with systemic disorders, and treatment outcomes. J. Pediatr., 165(4):8204.e2, 2014.

Stiglmayer, N.; Tojagic, M. \& Juri, J. Long-term results of frontal lobe suspension in children with congenital dystrophic ptosis. Coll. Antropol., 28(1):349-56, 2004.

Yang, H. M.; Hu, K. S. \& Kim, H. J. Anatomical and Functional Consideration of the Trigemino-Facial Nervous Communication and Facial Expresssion Muscles. Korean J. Phys. Anthropol., 26(1):1-12, 2013.

Zhao, T. I.; Yu, D. J.; Xie, X. M.; Zhang, Y. T.; Xu, Y.; Chen, Q. \& $\mathrm{Wu}, \mathrm{H}$. R. Improvement of frontal muscle-fascia suspension for blepharoptosis treatment. Zhongguo Meirong Yixue, 17(1):9-11, 2011.

Zhong, M.; Jin, R.; Li, Q.; Duan, Y.; Huang, L. \& Yu, D. Frontalis muscle flap advancement for correction of severe ptosis under general anesthesia: modified surgical design with 162 cases in China. Aesthetic Plast. Surg., 38(3):503-9, 2014.

\section{Correspondence to: \\ Xingchao Jiang \\ Department of Plastic Surgery \\ China-Japan Union Hospital of Jilin University \\ Changchun 130033 \\ CHINA}

Email: zbdoccn@163.com

\author{
Guang Zhang \\ Department of Thyroid Surgery \\ China-Japan Union Hospital of Jilin University \\ Changchun 130033 \\ CHINA
}

Email: zhangguang_74@163.com

Received: 03-08-2015

Accepted: 16-10-2015 